\title{
Family Environment Factors to Impact on the Effect of the Smoking Prevention Educational Program for Elementary and Junior High School Students
}

\author{
Kikuko Okudaa,2, Hiroki Okada ${ }^{3}$, Tetsuya Tanioka', Kyoko Osaka ${ }^{1}$ \\ ${ }^{1}$ Faculty of Nursing, Institute of Biomedical Sciences, Graduate School, Tokushima University, Tokushima, Japan \\ ${ }^{2}$ Graduate School of Medicine, Kagawa University, Kagawa, Japan \\ ${ }^{3}$ Faculty of Medicine, Graduate School of Medicine, Kagawa University, Kagawa, Japan \\ Email: okuda@tokushima-u.ac.jp
}

How to cite this paper: Okuda, K., Okada, H., Tanioka, T. and Osaka, K. (2018) Family Environment Factors to Impact on the Effect of the Smoking Prevention Educational Program for Elementary and Junior High School Students. Health, 10, 75-89. https://doi.org/10.4236/health.2018.101006

Received: December 3, 2017

Accepted: January 9, 2018

Published: January 12, 2018

Copyright (c) 2018 by authors and Scientific Research Publishing Inc. This work is licensed under the Creative Commons Attribution International License (CC BY 4.0).

http://creativecommons.org/licenses/by/4.0/

\begin{abstract}
Smoking is a major health problem in many countries. It has been reported on the effects of education on youth with a reduced smoking rate and developed awareness of avoiding smoking verified as a result of educational intervention. The aim of this study was to verify the relationship between sex, school age, and family smoking and the effectiveness of smoking prevention education program (SPEP) as factors that impact the effectiveness of SPEP in elementary school and junior high school students. The participants in this survey were 6676 students, who attended elementary and junior high schools in Tokushima Prefecture between 2011 and 2015, and attended the SPEP. As factors that influence the effectiveness of the SPEP, we examined school types, sex, smokers in the family. Participants were asked the following questions before and after the SPEP to measure awareness of and attitudes toward smoking: "intention not to smoke cigarettes as adults", "intention to refuse cigarettes when offered", "attitude of staying away from smokers", and "desire that their family will not smoke". The number of survey collected was 6676, with effective responses from 5974 (90\%). Among the 5974, there were 2963 (50\%) males and 3011 (50\%) females, 5106 elementary school students (86\%), and 868 junior high school students (15\%). Findings showed that having smokers in the family affects not only children's intention and attitude toward smoking, but also the effectiveness of smoking prevention education. Especially, it was difficult to improve children's "intention not to smoke as adults", "intention to refuse cigarettes when offered", "attitude of staying away from smoke-
\end{abstract}


rs", and "desire that their family will not smoke". Therefore, it was thought that SPEP to be less effective, in mentioned situation, in improving awareness of and attitudes toward smoking among elementary and junior high school students.

\section{Keywords}

Smoking Preventing Education, Elementary Students, Junior High Students, Family Environment

\section{Introduction}

The causal relationship between smoking and diseases has been elucidated. Smoking is a major health problem in many countries [1] [2]. Therefore, health education on smoking is required [3]. According to the survey conducted by the Ministry of Health, Labor, and Welfare, the smoking rate has decreased in the last 10 years, and was $19.8 \%$ in 2017 [4]. Nevertheless, the smoking rate among males in their $30 \mathrm{~s}$ to $40 \mathrm{~s}$ is around $40 \%$, which places Japan above many OECD member countries [5]. Furthermore, health damage from cigarettes is not limited to the smokers themselves: harm caused by passive smoking through secondhand smoke and exhaled smoke cannot be overlooked [6] [7] [8].

To reduce health damage from cigarettes, Japan implemented a national policy aimed at development and enlightenment as part of Health Japan 21 and the Health Promotion Act. In Japan, it is also mandatory to provide smoking prevention education program (SPEP) during the early stages of schooling.

Many countries have already reported on the effects of education on youth [9] [10] [11] [12], with a reduced smoking rate and developed awareness of avoiding smoking verified as a result of educational intervention [13]. In Japan, smoking is legally allowed over 20 years of age, but the current SPEP is provided in almost all elementary schools from third grade.

Nevertheless, it has been reported that awareness of and attitudes toward smoking are influenced by family smoking habits and family environment [14] [15]. The aforementioned report mainly discusses the link between smoking by parents and their children. It reported that when parents smoke, it leads to early smoking behavior in children [16].

As such, it can be assumed that family environment and family smoking habits have an impact on the effectiveness of SPEP. It was thus decided in this study that it was necessary to focus on the family environmental factors that affect educational effectiveness, in order to ensure more effective SPEP for elementary school students and junior high school students.

The aim of this study was to verify the relationship between sex, school age, and family smoking and the effectiveness of SPEP as factors that impact the effectiveness of SPEP in elementary school and junior high school students. 


\section{Method}

\subsection{Participants}

The participants in this survey were 6676 students, who attended elementary and junior high schools in Tokushima Prefecture between 2011 and 2015, and attended the SPEP provided by instructors and issued by the Japan Medical Association.

\subsection{Measures}

As factors that influence the effectiveness of the SPEP, this study examined school types, sex, smokers in the family, family breakdown, conversation about smoking with the family, and intention to talk about SPEP with the family. Participants were asked the following questions before and after the SPEP to measure awareness of and attitudes toward smoking: "intention not to smoke cigarettes as adults", "intention to refuse cigarettes when offered", "attitude of staying away from smokers", and "desire that their family will not smoke". The authors designed the questionnaire based on the some previous studies [17] [18] and the curriculum guidelines provided by the ministry of education, culture, sports, science and technology. Developed questionnaire was obtained expert opinions from the Japanese Association of Smoking Control Science courtesy of its president. Moreover, it made modification to the question items after the preliminary survey to confirm this questionnaire's content validity and reliability.

The questionnaire was distributed and collected by homeroom teachers. A preliminary survey was conducted during the week before the SPEP and a post survey was conducted on the same day as the SPEP. The questionnaire was anonymous, but an ID number was used so that questionnaires from before and after the intervention could be linked.

\subsection{Implemented Smoking Prevention Educational Program}

It was conducted the SPEP with public elementary and junior high school students in Tokushima Prefecture from 2011 to 2015. The SPEP was implemented using the same contents (Introduction, History of cigarette, Adverse effects of smoking, Diseases due to smoking, Secondhand smoking, Role playing to refuse cigarettes when offered) issued by instructors from the Japan Medical Association, and delivered by professionals trained on the same program. The educational intervention was provided only once, and lasted 45 to 50 minutes.

\subsection{Statistical Analysis}

Defective answers were excluded, and the basic statistics was done. Four items on intention and attitudes toward smoking were used as dependent variables, while the independent variables were sex, school types, smokers in the family, conversation about smoking with the family, and intention to speak about the SPEP with the family. 
Through comparison of intentions and attitudes toward smoking before and after the intervention, we created a "continuation group", including those who already had the desired awareness and attitudes, an "improvement group", for those who improved after SPEP, and a "no improvement group" of those who showed no improvement after the SPEP.

The relationships were analyzed using the Pearson chi-square test, adjusted residual analysis. Some values for chi square test were calculated excluding missing values. Statistical analyses were performed using SPSS 20 (SPSS Inc., Chicago, IL, USA). The level of statistical significance was set at 0.05 .

A priori analysis for a chi-square test was conducted using the Statistical power analyses software: the $G *$ Power (version 3.1) [19]. Sufficient sample size using an alpha 0.05 , a power of 0.95 , and the required sample size was 172 based on the aforementioned assumptions.

\subsection{Ethical Considerations}

This research was approved by the University of Tokushima hospital clinical study Ethical Review Board (approval number 1248). Participants were notified that privacy would be protected as only aggregate data would be utilized in reporting of findings.

\section{Result}

\subsection{Demographic Data}

The participants' characteristics are shown in Table 1.

Table 1. Characteristics of 5974 participants.

\begin{tabular}{|c|c|c|}
\hline Items & $\mathrm{n}$ & $(\%)$ \\
\hline \multicolumn{3}{|l|}{ Gender } \\
\hline Male & 2963 & $(49.6)$ \\
\hline Female & 3011 & $(50.4)$ \\
\hline \multicolumn{3}{|l|}{ Classification } \\
\hline Elementary school & 5106 & $(85.5)$ \\
\hline Junior high school & 868 & $(14.5)$ \\
\hline \multicolumn{3}{|l|}{ Smoker in family } \\
\hline No & 2688 & $(45.0)$ \\
\hline Yes & 3286 & $(55.0)$ \\
\hline Father & 2365 & $(72.0)$ \\
\hline Mother & 1012 & $(30.8)$ \\
\hline Parents & 631 & $(19.2)$ \\
\hline \multicolumn{3}{|c|}{ Conversation about cigarettes with the family } \\
\hline Yes & 3452 & $(57.8)$ \\
\hline No & 2522 & $(42.2)$ \\
\hline \multicolumn{3}{|c|}{ Intention to speak about SPEP with family } \\
\hline Yes & 3702 & 62.0 \\
\hline No & 2272 & 38.0 \\
\hline
\end{tabular}


The number of survey collected was 6676, with effective responses from 5974 (90\%). Among the 5974, there were 2963 (50\%) males and 3011 (50\%) females, 5106 elementary school students (86\%), and 868 junior high school students (15\%).

In response to the question on "smokers in the family", 3286 (55\%) responded "yes". Among these students, 2365 (72\%) said their fathers smoke, $1012(31 \%)$ said their mothers smoke and 631 reported that (19\%) both parents smoke.

In response to the question on "conversation about cigarettes with the family", 3452 (58\%) responded "yes", while 2522 (42\%) responded "no".

In response to the question on "intention to speak about SPEP with the family", 3702 (62\%) said "yes", while 2272 (38\%) said "no".

\subsection{Improvement in Awareness of and Attitudes toward Smoking Link to Attributes, Smokers in the Family, and Conversation with the Family}

As shown in Table 2, there was significant difference between school types ( $\mathrm{p}<$ $0.042)$ compared to all the other items $(\mathrm{p}<0.001)$ in the $(1)$ "intention not to smoke as adult".

Table 2. Relationship between "Intention not to smoke cigarettes as adults" and "Intention to refuse cigarettes when offered" and attributes, smokers in the family, and conversation with the family.

\begin{tabular}{|c|c|c|c|c|c|c|c|c|c|c|}
\hline & & & Good & huation & & ove & No $\mathrm{i}$ & rove & & \\
\hline & & & $\mathrm{n}$ & $\%$ & $\mathrm{n}$ & $\%$ & $\mathrm{n}$ & $\%$ & & \\
\hline & & & & & & & & & & \\
\hline 1 & Intention not to si & cigarettes as adults & & & & & & & & \\
\hline & Gender & Male & 1556 & $52.5 \%$ & 516 & $17.4 \%$ & 891 & $30.1 \%$ & 106.722 & $<0.001$ \\
\hline & & & -9.8 & & 2.3 & & 9.2 & & & \\
\hline & & Female & 1956 & $65.0 \%$ & 458 & $15.2 \%$ & 597 & $19.8 \%$ & & \\
\hline & & & 9.8 & & -2.3 & & -9.2 & & & \\
\hline & Classification & Elementary school & 3033 & $59.4 \%$ & 812 & $15.9 \%$ & 1261 & $24.7 \%$ & 6.343 & 0.042 \\
\hline & & & 2.3 & & -2.0 & & -0.9 & & & \\
\hline & & Junior high school & 479 & $55.2 \%$ & 162 & $18.7 \%$ & 227 & $26.2 \%$ & & \\
\hline & & & -2.3 & & 2.0 & & 0.9 & & & \\
\hline & Conversation & Yes & 2111 & $61.2 \%$ & 546 & $15.8 \%$ & 795 & $23.0 \%$ & 20.545 & $<0.001$ \\
\hline & about cigarettes & & 4.3 & & -1.2 & & -3.9 & & & \\
\hline & with the family & No & 1401 & $55.6 \%$ & 428 & $17.0 \%$ & 693 & $27.5 \%$ & & \\
\hline & & & -4.3 & & 1.2 & & 3.9 & & & \\
\hline & Intention to speak & Yes & 2376 & $64.2 \%$ & 661 & $17.9 \%$ & 665 & $18.0 \%$ & 251.009 & $<0.001$ \\
\hline & about SPEP & & 10.8 & & 4.1 & & -15.8 & & & \\
\hline & with family & No & 1136 & $50.0 \%$ & 313 & $13.8 \%$ & 823 & $36.2 \%$ & & \\
\hline & & & -10.8 & & -4.1 & & 15.8 & & & \\
\hline
\end{tabular}




\section{Continued}

\begin{tabular}{|c|c|c|c|c|c|c|c|c|c|}
\hline \multirow[t]{10}{*}{ Smoker in family } & No & 1778 & $66.1 \%$ & 375 & $14.0 \%$ & 535 & $19.9 \%$ & 110.738 & $<0.001$ \\
\hline & & 10.4 & & -4.5 & & -8.1 & & & \\
\hline & Yes & 1734 & $52.8 \%$ & 599 & $18.2 \%$ & 953 & $29.0 \%$ & & \\
\hline & & -10.4 & & 4.5 & & 8.1 & & & \\
\hline & Father & 1212 & $51.2 \%$ & 441 & $18.6 \%$ & 712 & $30.1 \%$ & 93.509 & $<0.001$ \\
\hline & & -9.6 & & 4.0 & & 7.5 & & & \\
\hline & Mother & 437 & $43.2 \%$ & 214 & $21.1 \%$ & 361 & $35.7 \%$ & 124.676 & $<0.001$ \\
\hline & & -11.1 & & 4.6 & & 8.7 & & & \\
\hline & Parents & 264 & $41.8 \%$ & 137 & $21.7 \%$ & 230 & $36.5 \%$ & 84.867 & $<0.001$ \\
\hline & & -9.1 & & 3.9 & & 7.1 & & & \\
\hline \multicolumn{10}{|c|}{ Intention to refuse cigarettes when offered } \\
\hline \multirow[t]{4}{*}{ Gender } & Male & 1768 & $59.7 \%$ & 499 & $16.8 \%$ & 696 & $23.5 \%$ & 44.882 & $<0.001$ \\
\hline & & -6.0 & & 1.1 & & 6.2 & & & \\
\hline & Female & 2022 & $67.2 \%$ & 476 & $15.8 \%$ & 513 & $17.0 \%$ & & \\
\hline & & 6.0 & & -1.1 & & -6.2 & & & \\
\hline \multirow[t]{4}{*}{ Classification } & Elementary school & 3262 & $63.9 \%$ & 822 & $16.1 \%$ & 1022 & $20.0 \%$ & 3.010 & 0.222 \\
\hline & & 1.7 & & -1.1 & & -1.0 & & & \\
\hline & Junior high school & 528 & $60.8 \%$ & 153 & $17.6 \%$ & 187 & $21.5 \%$ & & \\
\hline & & -1.7 & & 1.1 & & 1.0 & & & \\
\hline Conversation & Yes & 2299 & $66.6 \%$ & 509 & $14.7 \%$ & 644 & $18.7 \%$ & 35.399 & $<0.001$ \\
\hline about cigarettes & & 5.9 & & -3.9 & & -3.6 & & & \\
\hline \multirow[t]{2}{*}{ with the family } & No & 1491 & $59.1 \%$ & 466 & $18.5 \%$ & 565 & $22.4 \%$ & & \\
\hline & & -5.9 & & 3.9 & & 3.6 & & & \\
\hline Intention to speak & Yes & 2596 & $70.1 \%$ & 613 & $16.6 \%$ & 493 & $13.3 \%$ & 299.223 & $<0.001$ \\
\hline about SPEP & & 13.7 & & 0.6 & & -17.0 & & & \\
\hline \multirow[t]{2}{*}{ with family } & No & 1194 & $52.6 \%$ & 362 & $15.9 \%$ & 716 & $31.5 \%$ & & \\
\hline & & -13.7 & & -.6 & & 17.0 & & & \\
\hline \multirow[t]{10}{*}{ Smoker in family } & No & 1782 & $66.3 \%$ & 441 & $16.4 \%$ & 465 & $17.3 \%$ & 27.144 & $<0.001$ \\
\hline & & 4.1 & & 0.2 & & -5.1 & & & \\
\hline & Yes & 2008 & $61.1 \%$ & 534 & $16.3 \%$ & 744 & $22.6 \%$ & & \\
\hline & & -4.1 & & -0.2 & & 5.1 & & & \\
\hline & Father & 1406 & $59.5 \%$ & 402 & $17.0 \%$ & 557 & $23.6 \%$ & 32.176 & $<0.001$ \\
\hline & & -5.2 & & 1.1 & & 5.2 & & & \\
\hline & Mother & 580 & $57.3 \%$ & 160 & $15.8 \%$ & 272 & $26.9 \%$ & 33.952 & $<0.001$ \\
\hline & & -4.4 & & -0.5 & & 5.8 & & & \\
\hline & Parents & 357 & $56.6 \%$ & 104 & $16.5 \%$ & 170 & $26.9 \%$ & 20.918 & $<0.001$ \\
\hline & & -3.8 & & 0.1 & & 4.4 & & & \\
\hline
\end{tabular}

The relationships were analyzed using the Pearson chi-square test, adjusted residual analysis. ARV: adjusted residual value. For "Smoker in family" shown in italics (Father, Mother, Parents), it indicates attributes of those who answered "Yes". These values were separately analyzed each Pearson chi-square test values and its adjusted residuals. 
Looking at (2) "intention to refuse cigarettes when offered", 1022 (20\%) elementary school children and 187 (22\%) of junior high school students showed no improvement; thus, there was no significant difference between the two age groups. There was, however, significant difference in all the other items $(\mathrm{p}<$ 0.001).

As shown in Table 3, there was no significant difference in school types with regard to (1) "attitude of staying away from smokers": 2019 (40\%) of elementary school students showed no improvement while 326 (38\%) of junior high school students showed no improvement. There was significant difference in "conversation about cigarettes with the family" $(\mathrm{p}<0.002)$ and in other items $(\mathrm{p}<$ $0.001)$.

Table 3. Relationship between "Attitude of staying away from smokers" and "Desire that their family will not smoke" and attributes, smokers in the family, and conversation with the family.

\begin{tabular}{|c|c|c|c|c|c|c|c|c|c|c|}
\hline & & & \multicolumn{2}{|c|}{ Good continuation } & \multicolumn{2}{|c|}{ Improve } & \multicolumn{2}{|c|}{ No improve } & \multirow{3}{*}{$\chi^{2}$} & \multirow{3}{*}{$\mathrm{p}$} \\
\hline & \multicolumn{2}{|c|}{ Items } & $\mathrm{n}$ & $\%$ & $\mathrm{n}$ & $\%$ & $\mathrm{n}$ & $\%$ & & \\
\hline & & & \multicolumn{2}{|c|}{ ARV } & \multicolumn{2}{|c|}{ ARV } & \multicolumn{2}{|c|}{ ARV } & & \\
\hline 1 & \multicolumn{10}{|c|}{ Attitude of staying away from smokers } \\
\hline & \multirow[t]{4}{*}{ Gender } & Male & 1046 & $35.3 \%$ & 670 & $22.6 \%$ & 1247 & $42.1 \%$ & 19.925 & $<0.001$ \\
\hline & & & -3.1 & & -1.6 & & 4.4 & & & \\
\hline & & Female & 1178 & $39.1 \%$ & 735 & $24.4 \%$ & 1098 & $36.5 \%$ & & \\
\hline & & & 3.1 & & 1.6 & & -4.4 & & & \\
\hline & \multirow[t]{4}{*}{ Classification } & Elementary school & 1900 & $37.2 \%$ & 1187 & $23.2 \%$ & 2019 & $39.5 \%$ & 1.847 & 0.397 \\
\hline & & & -0.1 & & -1.2 & & 1.1 & & & \\
\hline & & Junior high school & 324 & $37.3 \%$ & 218 & $25.1 \%$ & 326 & $37.6 \%$ & & \\
\hline & & & 0.1 & & 1.2 & & -1.1 & & & \\
\hline & Conversation & Yes & 1344 & $38.9 \%$ & 811 & $23.5 \%$ & 1297 & $37.6 \%$ & 12.281 & \\
\hline & about cigarettes & & 3.2 & & -0.1 & & -3.1 & & & \multirow{3}{*}{0.002} \\
\hline & \multirow[t]{2}{*}{ with the family } & No & 880 & $34.9 \%$ & 594 & $23.6 \%$ & 1048 & $41.6 \%$ & & \\
\hline & & & -3.2 & & 0.1 & & 3.1 & & & \\
\hline & Intention to speak & Yes & 1574 & $42.5 \%$ & 962 & $26.0 \%$ & 1166 & $31.5 \%$ & 247.565 & $<0.001$ \\
\hline & about SPEP & & 10.8 & & 5.7 & & -15.7 & & & \\
\hline & \multirow[t]{2}{*}{ with family } & No & 650 & $28.6 \%$ & 443 & $19.5 \%$ & 1179 & $51.9 \%$ & & \\
\hline & & & -10.8 & & -5.7 & & 15.7 & & & \\
\hline & \multirow[t]{4}{*}{ Smoker in family } & No & 1141 & $42.4 \%$ & 622 & $23.1 \%$ & 925 & $34.4 \%$ & 65.244 & $<0.001$ \\
\hline & & & 7.5 & & -0.6 & & -6.9 & & & \\
\hline & & Yes & 1083 & $33.0 \%$ & 783 & $23.8 \%$ & 1420 & $43.2 \%$ & & \\
\hline & & & -7.5 & & 0.6 & & 6.9 & & & \\
\hline
\end{tabular}




\section{Continued}

$\begin{array}{lcccccccc}\text { Father } & 755 & 31.9 \% & 558 & 23.6 \% & 1052 & 44.5 \% & 56.859 & <0.001 \\ & -6.9 & & .1 & & 6.7 & & & \\ \text { Mother } & 321 & 31.7 \% & 221 & 21.8 \% & 470 & 46.4 \% & 27.437 & <0.001 \\ & -4.0 & & -1.4 & & 5.1 & & & \\ \text { Parents } & 204 & 32.3 \% & 135 & 21.4 \% & 292 & 46.3 \% & 14.764 & 0.001 \\ & -2.7 & & -1.3 & & 3.8 & & & \end{array}$

2 Desire that their family will not smoke

\begin{tabular}{|c|c|c|c|c|c|c|c|c|c|}
\hline \multirow[t]{4}{*}{ Gender } & Male & 1403 & $47.4 \%$ & 576 & $19.4 \%$ & 984 & $33.2 \%$ & 29.218 & $<0.001$ \\
\hline & & -3.6 & & -1.7 & & 5.4 & & & \\
\hline & Female & 1565 & $52.0 \%$ & 639 & $21.2 \%$ & 807 & $26.8 \%$ & & \\
\hline & & 3.6 & & 1.7 & & -5.4 & & & \\
\hline \multirow[t]{4}{*}{ Classification } & Elementary school & 2541 & $49.8 \%$ & 1027 & $20.1 \%$ & 1538 & $30.1 \%$ & 1.155 & 0.561 \\
\hline & & 0.3 & & -1.0 & & 0.6 & & & \\
\hline & Junior high school & 427 & $49.2 \%$ & 188 & $21.7 \%$ & 253 & $29.1 \%$ & & \\
\hline & & -0.3 & & 1.0 & & -0.6 & & & \\
\hline Conversation & Yes & 1736 & $50.3 \%$ & 721 & $20.9 \%$ & 995 & $28.8 \%$ & 5.462 & 0.065 \\
\hline about cigarettes & & 1.1 & & 1.2 & & -2.3 & & & \\
\hline \multirow[t]{2}{*}{ with the family } & No & 1232 & $48.9 \%$ & 494 & $19.6 \%$ & 796 & $31.6 \%$ & & \\
\hline & & -1.1 & & -1.2 & & 2.3 & & & \\
\hline Intention to speak & Yes & 2017 & $54.5 \%$ & 834 & $22.5 \%$ & 851 & $23.0 \%$ & 226.889 & $<0.001$ \\
\hline about SPEP & & 9.5 & & 5.4 & & -15.1 & & & \\
\hline \multirow[t]{2}{*}{ with family } & No & 951 & $41.9 \%$ & 381 & $16.8 \%$ & 940 & $41.4 \%$ & & \\
\hline & & -9.5 & & -5.4 & & 15.1 & & & \\
\hline \multirow[t]{10}{*}{ Smoker in family } & No & 1889 & $70.3 \%$ & 362 & $13.5 \%$ & 437 & $16.3 \%$ & 837.519 & $<0.001$ \\
\hline & & 28.8 & & -11.9 & & -20.9 & & & \\
\hline & Yes & 1079 & $32.8 \%$ & 853 & $26.0 \%$ & 1354 & $41.2 \%$ & & \\
\hline & & -28.8 & & 11.9 & & 20.9 & & & \\
\hline & Father & 740 & $31.3 \%$ & 609 & $25.8 \%$ & 1016 & $43.0 \%$ & 542.940 & $<0.001$ \\
\hline & & -23.0 & & 8.4 & & 17.7 & & & \\
\hline & Mother & 282 & $27.9 \%$ & 246 & $24.3 \%$ & 484 & $47.8 \%$ & 255.599 & $<0.001$ \\
\hline & & -15.2 & & 3.4 & & 13.6 & & & \\
\hline & Parents & 170 & $26.9 \%$ & 150 & $23.8 \%$ & 311 & $49.3 \%$ & 165.248 & $<0.001$ \\
\hline & & -12.1 & & 2.3 & & 11.2 & & & \\
\hline
\end{tabular}

The relationships were analyzed using the Pearson chi-square test, adjusted residual analysis. ARV: adjusted residual value. For "Smoker in family" shown in italics (Father, Mother, Parents), it indicates attributes of those who answered "Yes". These values were separately analyzed each Pearson chi-square test values and its adjusted residuals. 
In response to (2) "desire that their family wouldn't smoke", there was no significant difference in school types: 1538 (30\%) of elementary school students showed no improvement, while 253 (29\%) junior high school students showed no improvement. In response to "conversation about cigarettes with the family", 995 (29\%) said "yes", while 796 (32\%) said "no", suggesting no significant difference; however, there was significant difference in other items $(\mathrm{p}<0.001)$.

The ratio of groups showing no improvement is presented below.

Comparing awareness of and attitudes toward smoking before and after according to sex showed that 891 (30\%) of male students showed no improvement in "intention not to smoke as adult" while 597 (20\%) female students showed no improvement.

For "intention to refuse cigarettes when offered", 696 (24\%) of male students and 513 (17\%) of female students did not show improvement.

For "attitude of staying away from smokers", 1247 (42\%) male students and 1,098 (37\%) female students did not show improvement.

For "desire that their family will not smoke", 984 (33\%) male students and 807 (27\%) female students showed no improvement. In all questions, the ratio of male students without improvement was higher than that of females.

As for school types, in response to the question of "intention not to smoke as adults", 1261 (25\%) elementary school students and 227 (26\%) junior high school students showed no improvement.

With regard to changes in awareness of and attitude toward smoking based on smokers in the family, in response to the question of "intention not to smoke as adults", 535 (20\%) of those without a smoker in the family showed no improvement, while $712(30 \%)$ of those whose father smokes showed no improvement, and $361(36 \%)$ of those whose mother smokes showed no improvement. In households where both parents smoke, 230 (37\%) showed no improvement.

For "intention to refuse cigarettes when offered", 465 (17\%) of those without smokers in the family showed no improvement, 557 (24\%) of those whose father smokes showed no improvement, 272 (27\%) of those whose mother smokes showed no improvement, and 170 (27\%) of those with both parents smoking showed no improvement.

For "intention to stay away from smokers", 925 (34\%) had no smoker in the family, 1052 (45\%) had a father smoking, 470 (46\%) had a mother smoking, and 292 (46\%) had both parents smoking.

For "desire that their family will not smoke", 437 (16\%) of those without smokers in the family showed no improvement, while 1016 (43\%) of those whose father smokes showed no improvement, 484 (48\%) of those whose mother smokes showed no improvement, and 311 (49\%) of those with both parents smoking showed no improvement.

As for awareness of and attitude toward smoking, assessed in the question of "conversation about cigarettes with the family", students who did not show any improvement in their intention not to smoke as adults included 693 (28\%) who 
did not have conversation with the family and 795 (23\%) who did.

In the group who did have conversation with their family, 644 (19\%) did not show improvement in "intention to refuse cigarettes when offered", while 565 $(22 \%)$ of those who did not have conversation showed no improvement. In the group who did have conversation with the family, 1297 (38\%) showed no improvement in "attitude of staying away from smokers", while 1048 (42\%) of those who did not have conversation showed no improvement.

For changes in awareness of cigarettes, assessed by the question "intention to talk about SPEP with the family", 665 (18\%) of students who intended to speak with their family showed no improvement in the intention not to smoke as adults, while 823 (36\%) who did not intend to speak with their family showed no improvement.

Among those students who intended to speak about the SPEP with their family, 493 (13\%) did not show improvement in "intention to refuse cigarettes when offered", com-pared to 716 (32\%) students who did not demonstrate intention and showed no improvement.

In the group of students who did intend to speak with their family, 1166 (32\%) showed no improvement in "attitude of staying away from smokers", while 1179 (52\%) of those who did not demonstrate intention showed no improvement. Among those in-tending to speak with their family, 851 (23\%) showed no improvement in the question "desire that their family will not smoke", while 940 (41\%) of those who did not demonstrate intention showed no improvement.

\section{Discussion}

In all items for which significant difference was noted in the chi-squared test, the adjusted residual value (ARV) was above 2.58 and was deemed significant, with a significance level of $1 \%$. This survey showed that SPEP improve their thinking of smoking. In this study, it focused on non-improvement factors in order to obtain further effects of SPEP, below.

The short-term effect of health education is said to be more apparent in female students than in male students [20], and age is also seen to make a difference in educational impact [9]. Furthermore, in previous surveys [21] [22] [23] [24] [25], it has been reported that the family smoking environment may impact the initial and future smoking habits of children.

In all items for which significant difference was noted in the chi-squared test, the adjusted residual value (ARV) was above 2.58 and was deemed significant, with a significance level of $1 \%$.

The ARV for no improvement in "intention not to smoke as adults" was 9.2 for males and $\mathbf{- 9 . 2}$ for females. Therefore, the intention not to smoke as adults is unlikely to improve in males, but likely to improve for females.

It has been reported that being male is a risk factor for starting to smoke [26]; our study thus confirmed that there is sex-based difference in the effects of the 
SPEP.

It has been pointed out that the smoking rate is higher in children whose family smokes [14] [15]. The ARV of "no improvement" with regard to smokers in the family was -8.1 for those without smokers, 7.5 for those whose fathers smoke, 8.7 for those whose mothers smoke, and 7.1 for those with both parents smoking. Therefore, if there is a smoker in the family, it is difficult to improve. In particular, the $36 \%$ of students with mothers who smoke did not improve; our result was thus similar to a report concluding that children with mothers who smoke have higher rate of smoking [25].

The ARV of students who did not converse with their family about smoking and showed no improvement was 3.6, and the ratio of no improvement in the intention not to smoke as adult was high.

It has been reported that, when there is limited conversation with the family and when the relationship with the family is poor, children are more likely to smoke [24] [26]. Those who did not talk to their family about what they learned from the SPEP had an ARV of 15.8 and did not show improvement, showing that it is difficult to improve with the SPEP in these circumstances. It was therefore assumed that the child's relationship with their family affects the effectiveness of the SPEP.

Compared to girls, boys are less likely to believe that smoking is 'definitely' bad for health, and express lower non-smoking intentions and a lower capacity to refuse cigarettes [27].

In the present survey, about $60 \%$ of male students and $70 \%$ of female students demonstrated a strong intention to refuse cigarettes when offered before the intervention. The ARVs of male students and female students who did not show improvement were 6.2 and -6.2 , showing that male students are less likely to improve.

The ARV of those without a smoker in the family who showed no improvement was -5.1. The ARV was 5.2 for those whose fathers smoke, 5.8 for those whose mothers smoke, and 4.4 if both parents smoke. It was considered that difficult to improve if there is a smoker in the family, especially if the mother has a smoking habit.

The ARV of those who had no intention to speak about the SPEP with their family but do now show improvement in refusing cigarettes was high: 17.0. The intention to speak about the SPEP with the family is strongly linked to the intention to refuse cigarettes when offered. Students who had difficulties speaking about the SPEP with the family found it more difficult to refuse cigarettes when offered.

The attitude of staying away from smokers is important in preventing harm from secondhand smoke. The ARV of male students was 4.4, and it is more difficult for male students to develop an attitude of staying away from smokers as a result of the SPEP.

The ARV of students whose fathers smoke and showed no improvement was 6.7, while it was 5.1 for those whose mothers smoke. It was 3.8 if both parents 
smoked. On the other hand, if there is not a smoker in the family, the ARV was -6.9. If there are one or more smoker(s) in the family, the tendency to improve the intention to stay away from smoker(s) is poor. Particularly when the father smoke, $45 \%$ showed no improvement, which suggests it is difficult to develop an awareness that one must stay away from smokers in this situation. The ARV of those who had no intention to speak about the SPEP with their family and showed no improvement was 15.7, demonstrating a link between intention to refuse cigarettes when offered and the intention to speak to the family about what they learned at school [28].

The desire for their family not to smoke was already high for about $50 \%$ of both male and female students. Nonetheless, the ARV of the group of male students who showed no improvement was 5.4, demonstrating that about $30 \%$ of male students did not change their desire about their family smoking habits as a result of the SPEP.

With regard to family smoking, the ARV of the group that did not show improvement in their desire for their family not to smoke was 17.7 for those whose fathers smoke, 13.6 for those whose mothers smoke, and 11.2 when both parents smoke. When there is one or more smokers in the family, the SPEP clearly does not significantly improve the desire for their family not to smoke. This indicates that when fathers smoke, children are less likely to show a desire for their family not to smoke.

As a result, the following factors were difficult to improve through the SPEP intervention for "male students", "junior high school students", and "children whose parents smoke": "intention not to smoke as adults", "intention to refuse cigarettes when offered", "attitude of staying away from smokers", and "desire that their family will not smoke".

The findings of this study showed some factors influenced the short term educational effect. Further study, it is necessary to clarify long term educational effect and factors influencing it.

\section{Conclusion}

Findings showed that having smokers in the family affects not only children's intention and attitude toward smoking, but also the effectiveness of smoking prevention education. Especially, it was difficult to improve children's "intention not to smoke as adults", "intention to refuse cigarettes when offered", "attitude of staying away from smokers", and "desire that their family will not smoke". Therefore, it was thought that SPEP to be less effective, in mentioned situation, in improving awareness of and attitudes toward smoking among elementary and junior high school students.

\section{Acknowledgements}

We would like to express our deep gratitude to everyone who cooperated in this research, including students and guardians who cooperated with the survey in carrying out this research. 


\section{Funding/Financial Disclosure}

This work was supported by JSPS KAKENHI Grant, Number JP23590743, and project code JP2359074300.

\section{References}

[1] Becher, H., Belau, M., Winkler, V. and Aigner, A. (2017) Estimating Lung Cancer Mortality Attributable to Second Hand Smoke Exposure in Germany. International Journal of Public Health. [Epub ahead of Print] https://doi.org/10.1007/s00038-017-1022-1

[2] Hitchman, S.C. and Fong, G.T. (2011) Gender Empowerment and Female-to-Male Smoking Prevalence Ratios. Bulletin of the World Health Organization, 89, 195-202. https://doi.org/10.2471/BLT.10.079905

[3] Cavelaars, A.E.J.M., Kunst, A.E., Geurts, J.J.M., Crialesi, R., Grötvedt, L., Helmert, U., Lahelma, E., Lundberg, O., Matheson, J., Mielck, A., Rasmussen, N.K., Regidor, E., Rosário-Giraldes, M., Spuhler, T. and Mackenbach, J.P. (2000) Educational Differences in Smoking International Comparison. BMJ, 2000, 320.

[4] Ministry of Health (2017) National Health and Nutrition Survey 2017. (In Japanese) http://www.mhlw.go.jp/stf/houdou/0000177189.html2017

[5] OECD (2017) Daily Smokers (Indicator).

[6] Richardson, C.G., Schwartz, J., Struik, L.L. and Bottorff, J.L. (2013) Adapting the Stage of Change Model to Investigate Adolescent Behavior Related to Reducing Second Hand Smoke Exposure. Open Journal of Preventive Medicine, 3, 160-164. https://doi.org/10.4236/ojpm.2013.32021

[7] Blanch, C., Fernández, E., Martínez-Sánchez, J.M., Ariza, C., López, M.J., Moncada, A., Schiaffino, A., Rajmil, L., Saltó, E., Pascual, J.A., Nebot, M. and RESPIR.NET Research Group (2013) Impact of a Multi-Level Intervention to Prevent Secondhand Smoke Exposure in Schoolchildren: A Randomized Cluster Community Trial. Preventive Medicine, 57, 585-590. https://doi.org/10.1016/j.ypmed.2013.07.018

[8] Saito, J., Tabuchi, T., Shibanuma, A., Yasuoka, J., Nakamura, M. and Jimba, M. (2015) 'Only Fathers Smoking' Contributes the Most to Socioeconomic Inequalities: Changes in Socioeconomic Inequalities in Infants' Exposure to Second Hand Smoke over Time in Japan. PLoS ONE, 10, e0139512. https://doi.org/10.1371/journal.pone.0139512

[9] McGeeEmail, C.E., Trigwell, J., Fairclough, S.J., Murphy, R.C., Porcellato, L., Ussher, M. and Foweather, L. (2016) Effect of a Sport-for-Health Intervention (SmokeFree Sports) on Smoking-Related Intentions and Cognitions among 9-10 Year Old Primary School Children: A Controlled Trial. BMC Public Health, 16, 445. https://doi.org/10.1186/s12889-016-3048-3

[10] Taylor, J., Taylor, A., Lewis, S., McNeill, A., Britton, J., Jones, L.L., Bauld, L., Parrott, S., Wu, Q., Szatkowski, L. and Bains, M. (2016) A Qualitative Evaluation of a Novel Intervention Using Insight into Tobacco Industry Tactics to Prevent the Uptake of Smoking in School-Aged Children. BMC Public Health, 26, 539. https://doi.org/10.1186/s12889-016-3205-8

[11] Brinker, T.J., Stamm-Balderjahn, S., Seeger, W. and Groneberg, D.A. (2014) Education against Tobacco (EAT): A Quasi-Experimental Prospective Evaluation of a Programme for Preventing Smoking in Secondary Schools Delivered by Medical Students: A Study Protocol. BMJ Open, 4, e004909.

https://doi.org/10.1136/bmjopen-2014-004909 
[12] Peterson Jr., A.V., Marek, P.M., Kealey, K.A., Bricker, J.B., Ludman, E.J. and Heffner, J.L. (2016) Does Effectiveness of Adolescent Smoking-Cessation Intervention Endure into Young Adulthood? 7-Year Follow-Up Results from a Group-Randomized Trial. PLoS ONE, 11, e0146459. https://doi.org/10.1371/journal.pone.0146459

[13] Thomas, R.E., McLellan, J. and Perera, R. (2013) School-Based Programmes for Preventing Smoking. Cochrane Database of Systematic Reviews, 4, CD001293. https://doi.org/10.1002/14651858.CD001293.pub3

[14] Žaloudíková, I., Hrubá, D. and Samara, I. (2012) Parental Education and Family Status-Association with Children's Cigarette Smoking. Central European Journal of Public Health, 20, 38-44. http://apps.szu.cz/svi/cejph/show_en.php?kat=archiv/2012-1-08

[15] Zaborskis, A. and Sirvyte, D. (2015) Familial Determinants of Current Smoking among Adolescents of Lithuania: A Cross-Sectional Survey 2014. BMC Public Health, 15, 889. https://doi.org/10.1186/s12889-015-2230-3

[16] Milton, B., Cook, P.A., Dugdill, L., Porcellato, L., Springett, J. and Woods, S.E. (2004) Why Do Primary School Children Smoke? A Longitudinal Analysis of Predictors of Smoking Uptake during Pre-Adolescence. Public Health, 118, 247-255. https://doi.org/10.1016/j.puhe.2003.10.006

[17] Ohmi, H. (2005) Effect of Educational Intervention in Senior High School Students by Public Health Center on Their Behavior and Beliefs about Smoking. The Journal of Child Health, 63, 570-576. (In Japanese)

[18] Eiichi, A. (2008) The Result of the Smoking Survey Conducted on Third Grade Students in Junior High School and the Tobacco Use Prevention Program Performed on Both Five Graders of Elementary School and Second Grader of Junior High School during the Past Ten Years. Japanese Journal of School Health, 50, 385-391. (In Japanese)

[19] Faul, F., Erdfelder, E., Lang, A.-G. and Buchner, A. (2007) G Power 3: A Flexible Statistical Power Analysis Program for the Social, Behavioral, and Biomedical Sciences. Behavior Research Methods, 39, 175-191. https://doi.org/10.3758/BF03193146

[20] Sugisaki, K., Ueda, S., Monobe, H., Yako-Suketomo, H., Eto, T., Watanabe, M. and Mori, R. (2014) Cancer Understanding among Japanese Students Based on a Nationwide Survey. Environmental Health and Preventive Medicine, 19, 395-404. https://doi.org/10.1007/s12199-014-0406-6

[21] Avenevoli, S. and Merikangas, K.R. (2003) Familial Influences on Adolescent Smoking. Addiction, 98, 1-20. https://doi.org/10.1046/j.1360-0443.98.s1.2.x

[22] Darling, N. and Cumsille, P. (2003) Theory, Measurement, and Methods in the Study of Family Influences on Adolescent Smoking. Addiction, 98, 21-36. https://doi.org/10.1046/j.1360-0443.98.s1.3.x

[23] Bricker, J.B., Leroux, B.G., Peterson, A.V., Kealey, K.A., Sarason, I.G., Andersen, M.R. and Marek, P.M. (2003) Nine-Year Prospective Relationship between Parental Smoking Cessation and Children's Daily Smoking. Addiction, 98, 585-593. https://doi.org/10.1046/j.1360-0443.2003.00343.x

[24] Chassin, L., Presson, C.C., Sherman, S.J., Montello, D. and McGrew, J. (1986) Changes in Peer and Parent Influence during Adolescence: Longitudinal versus Cross-Sectional Perspectives on Smoking Initiation. Developmental Psychology, 22, 327-334. https://doi.org/10.1037/0012-1649.22.3.327

[25] Barman, S.K., Pulkkinen, L., Kaprio, J. and Rose, R.J. (2004) Inattentiveness, Parental Smoking and Adolescent Smoking Initiation. Addiction, 99, 1049-1061. 
https://doi.org/10.1111/j.1360-0443.2004.00789.x

[26] Tucker, J.S., Ellickson, P.L. and Klein, D.J. (2003) Predictors of the Transition to Regular Smoking during Adolescence and Young Adulthood. Journal of Adolescent Health, 32, 314-324. https://doi.org/10.1016/S1054-139X(02)00709-7

[27] So, E.S. and Yeo, J.Y. (2015) Factors Associated with Early Smoking Initiation among Korean Adolescents. Asian Nursing Research, 9, 115-119. https://doi.org/10.1016/j.anr.2015.05.002

[28] Komro, K.A., McCarty, M.C., Forster, J.L., Blaine, T.M. and Chen, V. (2003) Parental, Family, and Home Characteristics Associated with Cigarette Smoking among Adolescents. American Journal of Health Promotion, 17, 291-299.

https://doi.org/10.4278/0890-1171-17.5.291 